\title{
Current Treatment of Filarial Cellulitis with Antibiotic Therapy-A Clinical Study
}

\author{
Kakarparthy Ravi Shankar', Mulla Divya Krupa² \\ ${ }^{1}$ Department of Pharmacy Practice, Sri Sai Aditya Institute of Pharmaceutical sciences and Research, Surampalem, Andhra Pradesh, \\ INDIA. \\ ${ }^{2}$ Department of Pharmacy Practice, Aditya Institute of Pharmaceutical sciences and Research, Surampalem, Andhra Pradesh, INDIA.
}

\begin{abstract}
Background: Cellulitis is defined as an inflammation of skin and soft tissue associated with bacterial infection ${ }^{1}$ lower limbs are majorly effected area. Several studies and case reports support the safe usage of antibiotics for the effective treatment of cellulitis. ${ }^{2}$ Objectives: In this study, authors mainly concern about the positive outcomes of cellulitis treatment with various antibiotics. Results: Clinical symptoms are reduced within one week of antibiotic treatment and all these antibiotics are well tolerated and there were no severe side effects observed during the course of therapy. Conclusion: Results of the study indicates that antibiotics are effective in the treatment of cellulitis.
\end{abstract}

Key words: Bullous Pemphigoid, Cellulitis, Lymphoedema, Mayalgia, Tenderness.

\section{INTRODUCTION}

Cellulitis is inflammation of loose connective tissue usually with a bacterial cause. It mostly refers to inflammation of subcutaneous layer of the skin. ${ }^{3}$ Most infections that affect intact skin are thought to be due to streptococci. ${ }^{4,5}$ Cellulitis of leg is a common medical emergency characterized by swelling, edema, fever. ${ }^{6}$ The most frequent causative organisms for celllulitis is staphylococci and streptococci. ${ }^{7,8}$ Even though there are several factors predispose to cellulitis and are probably operative in the pathogenesis of the illness, how these factors predispose patients to cellulitis is completely not known. Risk factors for cellulitis includes Diabetes, Lymphoedema / chronic oedema, primary or secondary Insect bites, Skin trauma/ulcers, Blistering disordersbullous pemphigoid (an acute or chronic autoimmune skin disease, involving the formation of blisters, more appropriately known as bullae), bullous impetigo, Animal bites, Skin rash-venous stasis eczema, athlete's foot (tineapedis), dry skin, obesity, recent surgery, immunodeficiency ${ }^{9}$ (cancer, kidney and liver disease, peripheral vascular disease), immunosuppressive drugs.

The affected area is red due to the inflammation and there may be warmth over it. Tight, glossy, "stretched" appearance of the skin is commonly seen. Pain or tenderness of the affected area is also seen. Other symptoms that may be seen include fever (with or without chills), sweating, fatigue, muscle pains (myalgia) and malaise. Occasionally, local lymph nodes may be swollen. Cellulitis can be diagnosed by physical examination, blood tests, $x$ - ray \& imaging studies. The doctor may try to draw fluid from the affected area with a needle and send the fluid to the laboratory for a culture. There are different types of treatment options available for cellulitis - antibiotics, anti-inflammatory medications, analgesics. Steroids are also included in the treatment.

\section{CASE 1}

A 65 year male patient presented to Department of Surgery, GGH KAKINADA, with chief complaints of swelling and discol-
Submitted date :24-Mar-2015 Accepted date :29-Mar-2015

DOI: 10.5530/ijopp.8.1.9

Address for correspondence:

Mrs. Mulla Divya Krupa,

Assistantprofessor,

Department of Pharmacy Practice,

Aditya Institute of Pharmaceutical sciences and Research.

Surampalem, Andhra Pradesh, INDIA.

E-mail:divyapharma.m@ gmail.com 


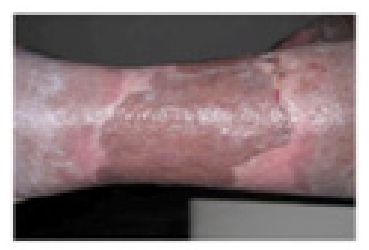

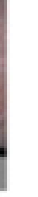

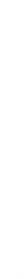

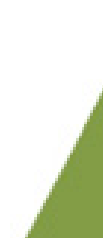

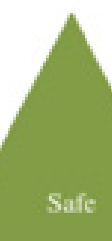

Before treatment
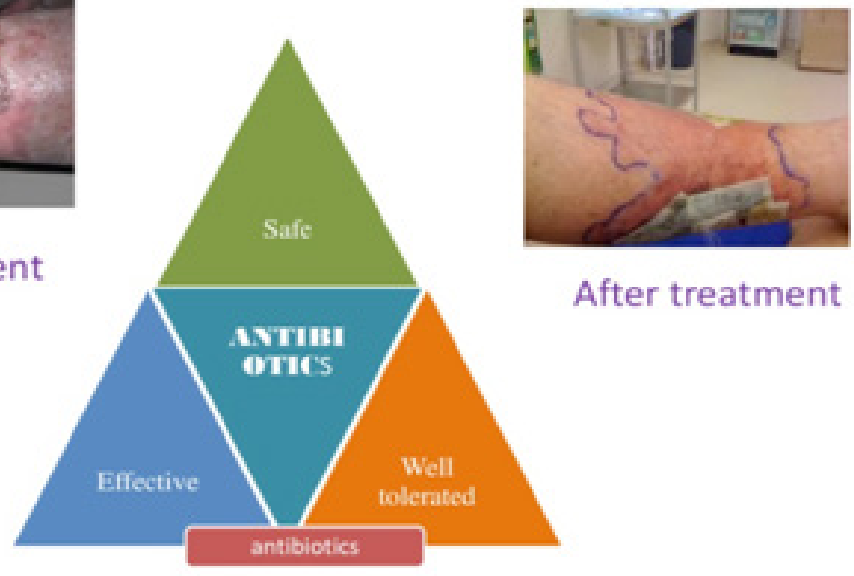

After treatment

\section{ANTIBIOTIC TIER.MPY IN CElluLuts}

Cellulitis is inflammation of skin and soft tissue mainly occurs because of bacterial infection. Patients presents with symptoms include swelling, redness, local warmth. Upon antibiotic use symptoms are reduced with no severe side effects. Antibiotics are better choice of drugs for the treatment of cellulitis

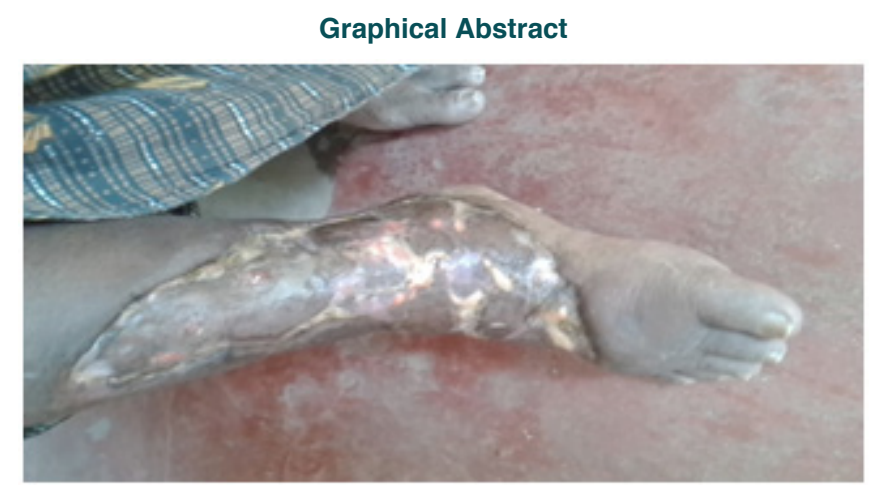

Figure 1: CELLULITIS WITH RIGHT LEG FILARIA

oration of right foot since 3 days. History of present illness started as swelling of right foot increased day by day, swelling extends towards the knee and is associated with discoloration of remaining foot. On the first day of examination watery discharge from swollen area of foot, generalized edema, visible scar is present lateral to ankle joint, stretching of skin, shiny appearance of skin, local rise in temperature, skin was peeled off in some areas, reduced urinary output was observed. Laboratory investigations reported Random Blood Sugar-170 mg/dl, Blood Urea Nitrogen-64 mg/dl, Serum Creatinine-2 mg/dl, Blood Pressure-110/70 mmHg, Pulse Rate - 80/min. Microscopy reveals that pus cells \& Gram negative bacteria (E.coli), Gram positive bacteria (Staphylococcus) are isolated. The patient was diagnosed as CELLULITIS WITH RIGHT LEG FILARIA. (Table 1) (Figure 1).
Initially vertical incision was given over prominent tissue area $(5 \mathrm{~cm})$ a clear fluid was drained, squeezing of leg was done. Betadine dressing was done regularly. After that following drug treatment is given.

\section{CASE 2}

A 60 year female patient presented to surgery ward with chief complaints of fever since 10 days, swelling in left thigh region since 10 days and severe headache. She reported having fevers, chills, and persistent nausea and vomiting for three days prior to being brought to hospital. Initially swelling started, gradually increased in size it breaks at tip \& progress to multiple pus forming tissue which rupture spontaneously. At the time of admission patient reported local rise in temperature, tenderness, swelling in left thigh region. Laboratory data reveals that herRandom Blood Sugar-350 mg/dl, Blood Pressure-120/80 mmHg, Pulse Rate $-82 / \mathrm{min}$. The patient was diagnosed as FILARIAL CELLULITIS. (Table 2). Indian Journal of Pharmacy Practice, Vol 8, Issue 1, Jan-Mar, 2015 


\begin{tabular}{lccccccccc}
\multicolumn{1}{l}{ Table 1: Drug therapy includes } \\
\multicolumn{1}{c}{ Drug } & ROA & Dose & Frequency & Day 1 & Day 2 & Day 3 & Day 4 & Day 5 & Day 6 \\
\hline Sulbacef & I.V & $5 \mathrm{gm}$ & B.D & Ö & Ö & O & O & O & Ö \\
Ceftrioxone & I.V & $1 \mathrm{gm}$ & B.D & O & Ö & Ö & Ö & Ö & Ö \\
Metrogyl & I.V & $100 \mathrm{ml}$ & T.I.D & O & O & O & - & - & - \\
Paracetamol & Tab & $500 \mathrm{mg}$ & T.I.D & O & O & Ö & - & - & - \\
D.E.C & Tab & $3 \mathrm{gm}$ & T.I.D & O & O & O & O & O & Ö \\
\hline
\end{tabular}

\begin{tabular}{lccccccccc}
\multicolumn{1}{l}{ Table 2: Drug therapy includes } \\
\multicolumn{1}{c}{ Drug } & ROA & Dose & Frequency & Day 1 & Day 2 & Day3 & Day 4 & Day 5 & Day 6 \\
\hline Sulbacef & I.V & $1.5 \mathrm{gm}$ & B.D & O & O & O & O & O & O \\
Ceftrioxone & I.V & $1 \mathrm{gm}$ & B.D & O & Ö & Ö & O & O & Ö \\
Metrogyl & I.V & $100 \mathrm{ml}$ & T.I.D & O & O & O & - & - & - \\
D.E.C & Tab & $2 \mathrm{gm}$ & T.I.D & O & O & Ö & O & O & Ö \\
Zofer & I.V & $500 \mathrm{mg}$ & T.I.D & O & O & O & - & - & - \\
Tramadol & I.V & - & B.D & O & O & - & - & - & - \\
\hline
\end{tabular}

\begin{tabular}{lccccccccc}
\multicolumn{1}{c}{ Table 3: Drug therapy includes } \\
\multicolumn{1}{c}{ Drug } & ROA & Dose & Frequency & Day 1 & Day 2 & Day3 & Day 4 & Day 5 & Day 6 \\
\hline Sulbacef & I.V & $1.5 \mathrm{gm}$ & B.D & Ö & Ö & Ö & Ö & Ö & Ö \\
Cefixime & Tab & $200 \mathrm{mg}$ & B.D & - & - & - & - & Ö & Ö \\
Metrogyl & I.V & $100 \mathrm{ml}$ & T.I.D & O & O & O & - & - & - \\
Paracetamol & Tab & $500 \mathrm{mg}$ & T.I.D & - & - & - & - & Ö & Ö \\
Amikacin & I.V & $500 \mathrm{mg}$ & B.D & - & O & O & Ö & Ö & - \\
D.E.C & Tab & $2 \mathrm{gm}$ & T.I.D & Ö & O & O & Ö & Ö & Ö \\
\hline
\end{tabular}

\section{CASE 3}

A 38 year female patients presented to surgery ward with chief complaints of ulcer on right great toe since 6 months, swelling of right foot since 3 months and gradually increased, fever since last 5 days. No history of similar complaints in past. She was a known diabetic since 8 years and taking medication for that. On physical examination patient was afebrile, conscious, and coherent, $1 \mathrm{x} 1 \mathrm{~cm}$ ulcer is present under the right great toe which is granulomatous. She reported her Blood Pressure: 110/70 mm Hg; Pulse Rate: 70/min; Random Blood Sugar: $171 \mathrm{mg} / \mathrm{dl}$; Hb: $9.9 \mathrm{gm} \%$; Blood Urea Nitrogen: $28 \mathrm{mg} / \mathrm{dl}$; Serum Creatinine: $0.4 \mathrm{mg} / \mathrm{dl}$. The patient was diagnosed as DIABETIC FOOT CELLULITIS WITH FILARIA. (Table 3).

Along with drug therapy additional supportive care also given which includes vitamin-C, B. Complex, Iron Folic Acid twice daily and I.V fluids (NS, RL) in all the 3 cases.

\section{RESULTS \& DISCUSSION}

The etiology behind the cellulitis in these three cases is bacterial infection ${ }^{1}$. However, the most common cause in the developing world is filariasis, as it affects over 120 million people in 80 countries worldwide. ${ }^{10}$ In the above three cases patients presented with similar complaints and parenteral antibiotics are prescribed for each case. Patients were advised to take Sulbacef (cefaperazone sodium) depending upon the severity of the symptoms $5 \mathrm{gm}, 1.5 \mathrm{gm}$ and $1.5 \mathrm{gm}$ twice daily respectively, Ceftrioxone $1 \mathrm{gm} \mathrm{IV}$, is given twice daily for case 1,2 till discharge and Cefixime $200 \mathrm{mg}$ twice daily added for case 3 for the treatment of bacterial infection.Metrogyl $100 \mathrm{ml}$ IV was given three times daily to all three cases. Diethyl Carbamazine Citrate 2-3 gm is given as the patients were diagnosed with filarial. Paracetamol $500 \mathrm{mg}$ tablet three times a day is prescribed for fever which is a common feature in cellulitis. During the period of antibiotic treatment patient counseling is given to each patient regarding the disease condition and treatment pattern. Patients are enquired for adverse effects in all the three cases, but there are no significant adverse effects reported upon antibiotic treatment. The use of antibiotics sub sides the clinical symptoms of the patients like swelling, redness, local warmth within 7 days. Vitals stable from third day onwards. Supportive medication (IV fluids and vitamin supplements) was provided for faster relief and quick 
recovery. Patients feel better at the end of the antibiotic treatment and physicians are advised to continue antibiotics at home if necessary.

\section{CONCLUSION}

With intense wound care and systemic antibiotics, patients are gradually recovered, all the symptoms subsides and were discharged in 16 days with their cellulitis. We can conclude that antibiotics are effective in the treatment of cellulitis ${ }^{2}$ because they are safe, well tolerated and efficacious. Apart from antibiotics additional supportive therapy is given for quick recovery. They are advised to continue oral antibiotics if necessary to prevent recurrence. Physicians and other health care providers should be aware of cellulitis and its treatment. Patient counseling about cellulitis is very important otherwise it leads to severe complications like obstruction of lymphatic flow, sepsis (blood infections), surgery.

\section{CONFLICT OF INTEREST}

The author has no conflict of interest.

\section{ACKNOWLEDGEMENTS}

The authors would like to thank all the staff of Department of Surgey, GGH, KAKINADA for clinical support and help in the creation and presentation of case report. The authors appreciate the support of the patients and their family members for publishing these cases. Written consent was obtained from the patients.

\section{Highlights of Paper}

- Cellulitis is defined as an inflammation of skin and soft tissue associated with bacterial infection.

- Lower limbs are majorly effected area.

- Antibiotics are effective in the treatment of cellulitis because they are safe, well tolerated and efficacious.

- Supportive medication and patient counselling is helpful in faster recovery

\section{Author Profile}

- M. Divya Krupa: Working as Assistant Professor, Department of Pharmacy Practice, Aditya institute of Pharmaceutical Sciences and Research, Andhra Pradesh, and Ph.D scholar of Department of Pharmacy Practice, JNTUK, Kakinada, Andhra Pradesh. She has 2 nos. of journal paper; Acting as guide in two (2) ongoing projects of pharm.D.

- Dr. K. Ravi Shankar: Presently working as Principal, Department Of Pharmacy Practice, Sri Sai Aditya institute of Pharmaceutical Sciences and Research, Andhra Pradesh. He worked as Senior Pharmacist And Assistant Professor,EL-THOWRA Teaching Hospital Omar Mukthar University, Libya.. He has 55 nos. of journal paper; more than 10 invited talk; 1 book:Text Book of Clinical Pharmacy and Pharmacotherapeutics:7 no.s of ongoing research projects. Reviewer for various international and national journals like natural product research , African journal of pharmacy and pharmacology, Issues in Biological Sciences and Pharmaceutical Research and Journal of Medicine and Medical Sciences.

\section{REFERENCES}

1. Craig G, Gunderson MD. Cellulitis: Definition, Etiology, and Clinical Features. The American Journal of Medicine December 2011; 124(12): 1113-22.

2. Lasschuit DA, Kuzmich D, Caplan GA. Treatment of cellulitis in hospital in the home: a systematic review. OA Dermatology 2014 Jan 18; 2(1): 2.

3. Cellulitis what you ought to know Lucy Hedley Manju Netto The Pharmaceutical Journal August 2013; 291: 193/ URI: 11124586.

4. Jeng A, Beheshti M, Li J, Nathan R. The role of beta-hemolytic streptococci in causing diffuse, nonculturable cellulitis: a prospective investigation. Medicine (Baltimore) 2010; 89(1): 217-26.

5. Bernard P, Bedane C, Mounier M, Denis F, Catanzano G, Bonnetblanc JM. Streptococcal cause of erysipelas and cellulitis in adults: a microbiologic study using a direct immune fluorescence technique. Arch Dermatol. 1989; 125(6): 779-82.

6. Cox NH, Colver GB, Paterson WD. Management and morbidity of cellulitis of the leg. JR Soc Med. 1998 December; 91(12): 634-7. PMCID: PMC1296982

7. Bisno AL, Stevens DL. Streptococcal infection of skin and soft tissues N Engl J Med. 1996; 334(4): 240- 5.

8. Staphylococcus aureus is the most common identified cause of cellulitis: a systematic review S. CHIRA ${ }^{\text {al }}$ and L.G.MILLER ${ }^{\mathrm{A} 2 \mathrm{C} 1}$ Epidemiology and infection 2010; 138(03): 313-7.

9. www. nursingtimes.net/ 108 No 27 / Nursing Times 03.07.12

10. Lymphatic Filariasis: Center for Disease Control [http://www.cdc.gov/ncidod/ $\mathrm{dpd} /$ parasites/lymphaticfilariasis/index.htm] webcite 